Indexed by

\title{
CHIP FORMATION DURING THERMAL FRICTION TURN MILIING
}

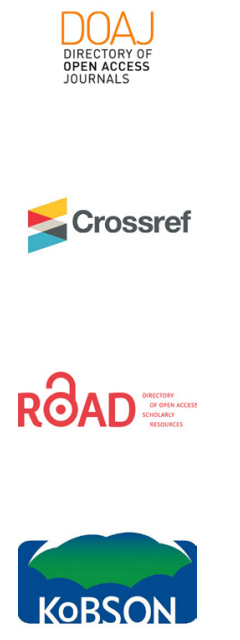

Medgat Mussayev

Karaganda Technical

University, Mechanical

Engineering faculty, department

"Technological equipment, mechanical engineering and standardization",

Karaganda, Kazakhstan

\section{Aybek Sherov \\ LIP «Kazakhstan Aviation \\ Industry», \\ Nur-Sultan, Kazakhstan}

\author{
Karibek Sherov \\ Karaganda Technical \\ University, Mechanical \\ Engineering faculty, department \\ "Technological equipment, \\ mechanical engineering and \\ standardization", \\ Karaganda, Kazakhstan

\section{Riza Gabdyssalik \\ D. Serikbayev East Kazakhstan University, Mechanical \\ Engineering faculty, Department of mechanical engineering, Ust-Kamenogorsk, Kazakhstan}

\author{
Aizhan Taskarina \\ Pavlodar University, \\ Mechanical Engineering faculty, \\ Department of Metallurgy, \\ Pavlodar, Kazakhstan
}

\author{
Toty Buzauova \\ Karaganda Technical \\ University, Mechanical \\ Engineering faculty, department \\ "Technological equipment, \\ mechanical engineering and \\ standardization", \\ Karaganda, Kazakhstan
}

\section{Saule Ainabekova}

Karaganda Technical University, Mechanical Engineering faculty, department "Technological equipment, mechanical engineering and standardization", Karaganda, Kazakhstan

Key words: thermofrictional turn-milling, chip root, structural angle, slowed-down layer, plastic defor-mation

\section{Cite article:}

Medgat, M., Karibek, S., Aizhan, T., Aybek, S., Riza, G., Toty, B., \& Saule, A. [2021]. Chip formation during thermal friction turn miliing. Journal of Applied Engineering Science, 19(1) 142 - 147. DOI: 10.5937/jaes0-27510

Online aceess of full paper is available at: www.engineeringscience.rs/browse-issues 


\title{
CHIP FORMATION DURING THERMAL FRICTION TURN MILIING
}

\author{
Medgat Mussayev', Karibek Sherov', Aizhan Taskarina'2, Aybek Sherov ${ }^{3}$, Riza Gabdyssalik, Toty Buzauova ${ }^{1}$, \\ Saule Ainabekova ${ }^{1}$ \\ ${ }^{1}$ Karaganda Technical University, Mechanical Engineering faculty, department "Technological equipment, \\ mechanical engineering and standardization", Karaganda, Kazakhstan \\ ${ }^{2}$ Pavlodar University, Mechanical Engineering faculty, Department of Metallurgy, Pavlodar, Kazakhstan \\ ${ }^{3}$ LIP «Kazakhstan Aviation Industry», Nur-Sultan, Kazakhstan \\ ${ }^{4}$ D.Serikbayev East Kazakhstan University, Mechanical Engineering faculty, Department of mechanical \\ engineering, Ust-Kamenogorsk, Kazakhstan
}

This paper presents the results of chip formation studies in the processing of 30KhGSA steel by thermofriction turn-milling. When studying the process in this work there are presented the results of studying chip formation when the processing of chip formation there is used the metallographic method. Chip root area investigated.The dependence of the chip shrinkage coefficient on the cutting speed and feed was also investigated. It is established that with increasing supply $S$ the value of the chip shrinkage coefficient $K$ decreases. The higher the chip shrinkage factor, the more work will be required to cut the chips and the more complex the processing process.

Key words: thermofrictional turn-milling, chip root, structural angle, slowed-down layer, plastic deformation

\section{INTRODUCTION}

The most important conditions of increasing the competitiveness of products are increasing productivity, decreasing expenses and improving quality in their production. When turning difficult-to-machine materials, one of the main reasons effecting the quality and productivity of cutting is formation of flow chips of various form and dimensions. With developing multipurpose lathes supplied with the tool head with the own drive there has appeared the possibility of implementing the operation of turn-milling that eliminates the mentioned difficulties $[1,2]$.

Within performing the grant subject: 2162/GF4 "Developing designs of a special machine permitting to feed pulse cooling and to replace the cutting tool made of a hard alloy by the tool made of constructional steel in thermo-frictional cutting metal billets" there has been studied the method of thermo-frictional turn-milling with the use of a special cutting tool: a frictional mill $[3,4,5,6,7]$.

One of the main differences of the developed way is the use of a special frictional mill made of non-instrumental material instead of standard face mills.

Studying the process of chip formation has both scientific-theoretical and practical value. It is especially important when developing new ways of machining where the results of studying chip formation can lead to improving structural elements of the cutting tool, as well as permits to explain and to use correctly in practice power and strength dependences. In this regard the work aimed at studying the mechanism of chip formation and strained state of the material when machining by thermo-frictional turn-milling is an urgent task.

\section{METHODOLOGY AND EQUIPMENT FOR CARRYING OUT THE STUDY}

The tasks stated in the work have been solved experimentally and theoretically. In theoretical studies there have been used basic provisions of the theory of cutting materials, theories of plasticity and elasticity, the theory of chip formation, technology of metals, materials science. In pilot studies there has been used metallographic method by microsections of chip roots.

The studies have been carried out with the use of the equipment of the Laboratories of Engineering Profile (LEP) and the MC of Karaganda Technical University.

In Figure 1 there are presented the photographs of the used equipment.

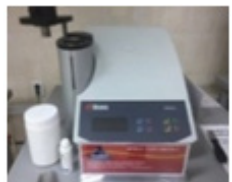

(a)

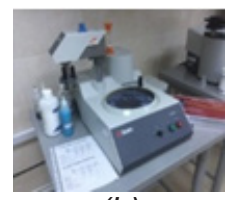

(b)

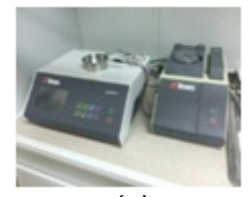

(c)

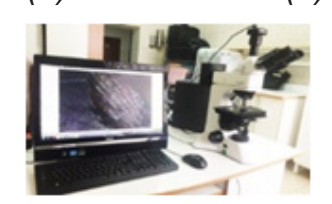

(d)

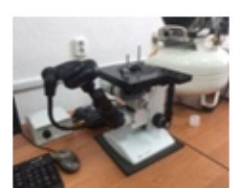

(e)
Figure 1: The used equipment photographs: CitoPress-1 press (a), LaboPol-5 automatic machine tool for samples grinding and polishing (b), automatic device for electrolytic polishing amd etching of metallographic samples (c), universal metallographic microscope Altami MET $5 T$ (d), metallographic microscope LOMO METAM RV-21 (e) 


\section{EXPERIMENTAL STUDY AND DISCUSSION}

When studying the process of cutting by the metallographic method there is carried out studying the slices of the chip roots and the machined surface [8]. The method permits to define changes of the chip structure and the structure of the layer adjacent to the machined surface. Observing changes of grains in the course of cutting, it is possible to gain an impression of the plastic deformation value in this or that area, the direction of the material stream, direction of shears. By means of this method there are revealed phase transformations happening in the chips and on the machined surface.

The studies show that the chip shapes (element or step) at the first stage of formation represent flow chips but variously deformed at the last stage. It is known that the extent of chops deformation depends on the properties of the machined material, the mode of cutting and geometry of the cutting tool. In the course of cutting the most intense zone and the zone of the largest pressure and intensive heat generation is the chip root zone where there is a contact of the cutting tool with the chips and with the machined part $[9,10,11,12]$. Cutting efforts, cutting heat, the cutting tool strength, the quality of the machined surface and other important factors shall have an immediate connection with the processes proceeding in the chip root zone [13,14]. Therefore studying the matter is of scientific and practical interest. In Figure 2 there are presented the photographs of chips obtained when machining 30 HGSA steel with various modes of cutting [7].
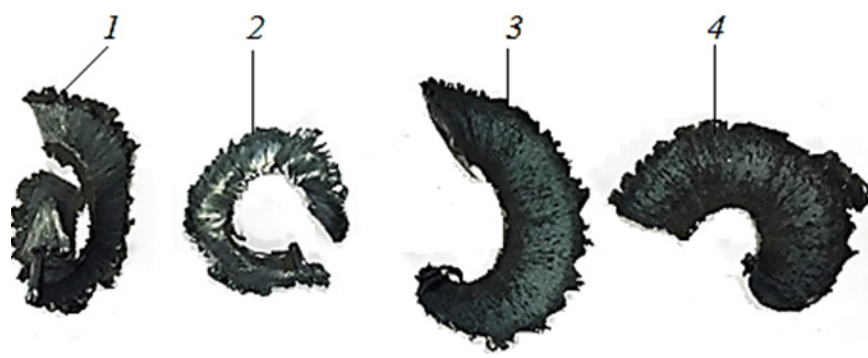

Figure 2: Photographs of the chips obtained when machining 30HGSA steel

For studying the chip texture there have been obtained chip samples of identical dimensions that makes fixing in automatic holders simple and convenient for the following stages. For this purpose there is carried out hot press fitting of chip samples on the CitoPress-1 press (see Figure $1 \mathrm{a}$ ) in which the sample, together with special pitch for press fitting is located in the press fitting cylinder.

In Figure 3 there are shown chip samples obtained after press fitting.
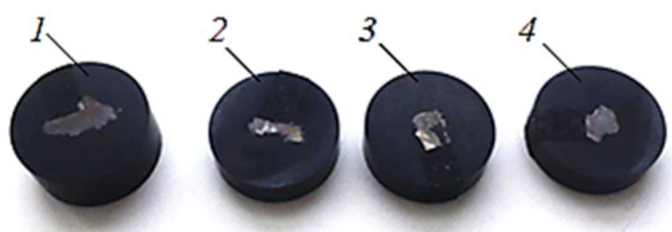

Figure 3: Chip samples obtained after press fitting
After press fitting chip samples there is performed grinding. Grinding is the most important operation in manufacturing techniques of samples. For grinding pressed samples there is used the grinding and polishing LaboPol-5 machine tool (see Figure 1b). Abrasive materials used when grinding are classified by the size of particles [15]. In the grinding process there is at first used the most fine-grained material and each subsequent operation of grinding has been followed by reducing the applied abrasive granularity. To improve the structure of the polished samples surface there has been used the electrolytic method of etching. This method of etching gives not only a brilliant smooth surface without formation peening or an amorphous layer, but it also reveals structural defects (pores, inclusions, etc.).

All the operations have been performed on the automatic device LectroPol-5 for electrolytic polishing and etching of metallographic samples (see Figure $1 \mathrm{c}$ ).

In Figure 4 there are shown the photographs of the chip samples texture obtained on the metallographic microscope LOMO METAM RV-21 (see Figure 1e).

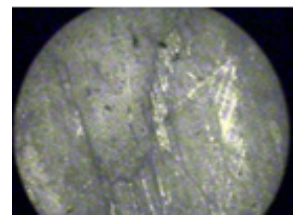

(a)

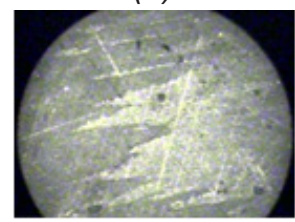

(c)

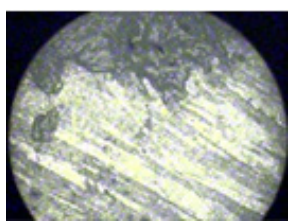

(b)

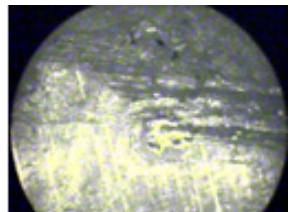

(d)
Figure 4: Chip samples texture photographs

In Figure 5 there are shown microphotographs (with 50X magnification) of the chip samples texture. They have been obtained on the universal metallographic microscope Altami MET 5T (see Figure 1d).

From the texture microphotograph it is seen that the texture lines are parallel to the forward surface and there are absent structural transformations when cutting. This is explained by the facts that such a short period is insufficient for structural transformations since in the course of

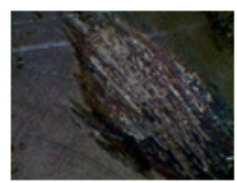

(a)

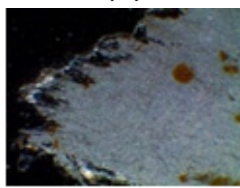

(c)

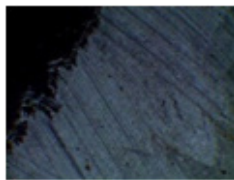

(b)

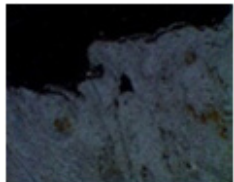

(d)
Figure 5: Microphotographs of the chip samples texture (with 50X magnification)

Istraživanja i projektovanja za privredu ISSN 1451-4117 Journal of Applied Engineering Science Vol. 19, No. 1, 2021 
thermo-frictional turn-milling the tool and the billet rotate simultaneously. The material in the contact layers keeps its initial phase state and undergoes changes only owing to plastic deformation. To obtain broader ideas of the process of chip formation in thermo-frictional turn-milling it is necessary to study the chip roots.

The chip roots are the direct proof of these or those processes happening in the zone of chip formation and in the contact zone. The studies are to cover a wide range of cutting speeds, only then it is possible to understand the transformation of mechanisms and processes in the cutting zone with changing the temperatures and speeds of deformation and to draw appropriate conclusions. Obtaining chip roots has happened at semi-fair turning of 30HGSA steel when feeding $S=30 \div 100$ of $\mathrm{mm} / \mathrm{min}$; the depth of cutting $t=1.5 \div 2.5 \mathrm{~mm}$; nsp=2000 rpm; $v_{s h}=250 \mathrm{~m} / \mathrm{min}$.

In Figure 6 there are shown microphotographs of chip roots obtained when cutting 30HGSA steel.

It is known $[16,17,18]$ that the basis of chip formation is mainly a simple shear. The direction of plastic shear is defined by the angle $\beta 1$ and the texture direction by the distortion of grains owing to relative shear turning them from spherical into ellipsoidal, and in a flat section from circles into ellipses.

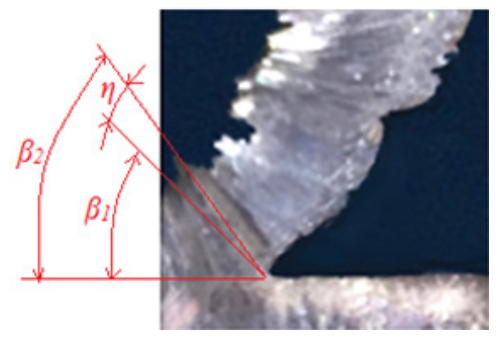

(a)

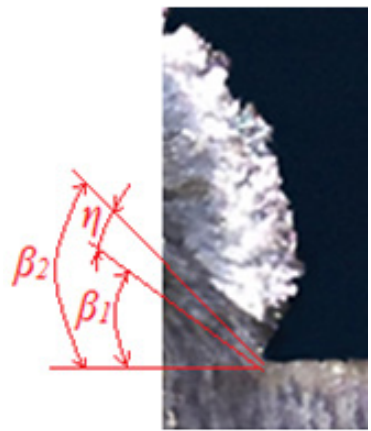

(b)

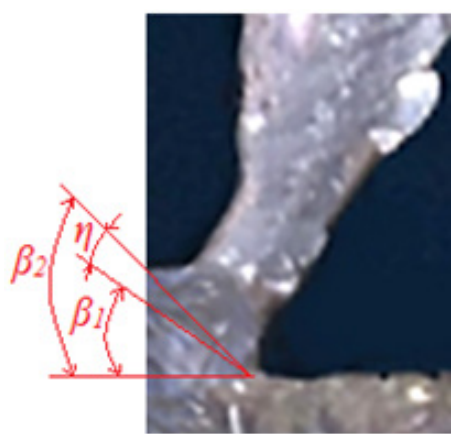

(c)

Figure 6: Microphotographs of the flow chip roots when cutting 30HGSA steel: shearing angle ( $\beta 1)$; structural line angle; $\eta$ - structural angle $(\beta 2)$

It is known $[16,17,18]$ that the basis of chip formation is mainly a simple shear. The direction of plastic shear is defined by the angle $\beta_{1}$ and the texture direction by the distortion of grains owing to relative shear turning them from spherical into ellipsoidal, and in a flat section from circles into ellipses.
In our case separate elements of the chip root are deformed in the direction which does not coincide with the position of the shear plane located at the angle $\beta_{1}$. The cut-off layer destruction happens in the shear plane (see Figure 5), and the greatest plastic deformation happens in the other direction, at the angle $\beta_{2}$ to this plane. The structural angle $\eta$ can be defined from the formula [17]:

$\operatorname{ctg} \eta=\varepsilon$

where $\varepsilon$ is the coefficient of relative shear.

The coefficient of relative shear is defined by the formula [17]:

$\varepsilon=\operatorname{ctg} \beta_{1}+\operatorname{tg}\left(\beta_{1}-\gamma\right)$

In the work by [19] Gux and Opits the results of the studies have shown in the plastically compressed material two directions of sliding with an angle between them $2 \varphi$ where the angle $\varphi$ is a constant of the material and there is the conclusion that one of these directions in chip formation is the shear direction $\beta_{1}$, and the other gives rise to the texture making with the first angle the $\eta$ angle determined by the formula:

$\eta=2 \phi-\lambda$

where $\lambda$ is the cutting edge dip angle.

$\lambda=\operatorname{arctg} \varepsilon$

The identity of element and flow chips in structural relation and the presence at those and other two angles $\beta_{1}$ and $\beta_{2}$ (see Figure 6 ) and three zones concerning the texture nature (see Figure 5 and 6 ) force to think that the nature of different chips formation is identical. To such a conclusion there also lead the reasons of unity of the cutting process, as well as the fact that in some cases the same chip includes both forms [17]: on the one hand, it is element, on the other hand it is flow.

The increase in feeding increases the extent of deformation of the contacting chip layer with the tool, therefore, there increases the amount of heat that is emitted owing to plastic deformation and cutting temperature. Therefore the chip material which is near the place of contact with the tool and is a raw material for the outgrowth is softened, becomes very plastic. At this the outgrowth won't arise, grow and become fragile to collapse, but will flow in a thin layer on the forward surface of the tool opposite to its movement aside. The outgrowth on the surface of the tool is in the plastic state and behaves as a pasty weight.

In Figure 7 there are shown the photographs of chip formation.

In the provided photographs it is seen that chip formation in thermo-frictional turn-milling has an ambiguous character. For the detailed discussion of the obtained results it is necessary to consider the diagram of chip formation presented in Figure 8.

Implementing the process of cutting in thermo-frictional turn-milling is based on the contact friction between the tool and the billet. Intensive deformation of grains happens in the ABCD section (see Figure 8). Zone 1 is more 


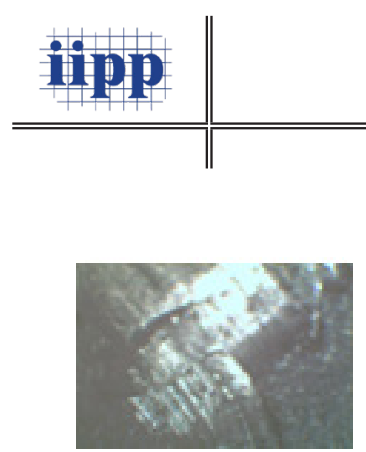

(a)

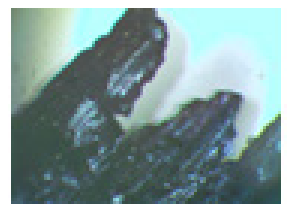

(f)

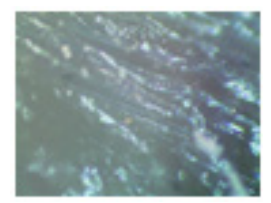

(b)

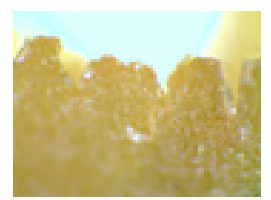

(g)

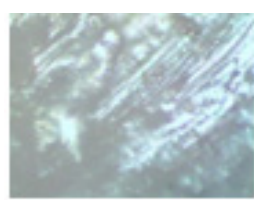

(c)

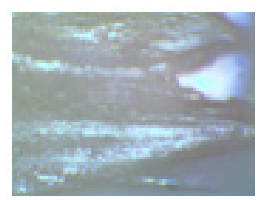

(h)

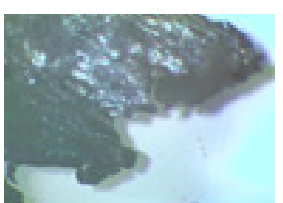

(d)

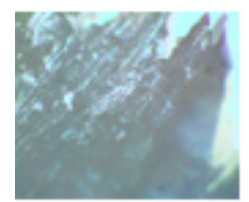

(e)

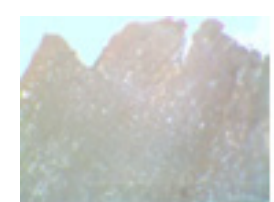

(I)

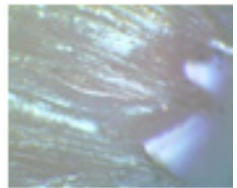

(m)

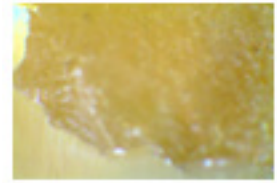

(i)

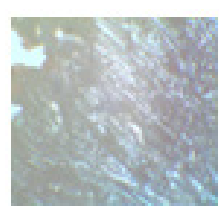

(k)

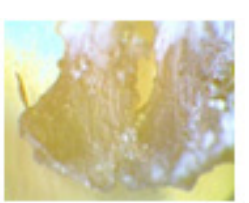

(n)

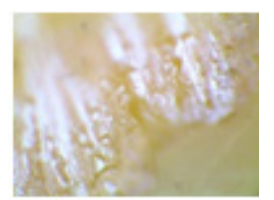

(o)

Figure 7: Chip formation photos

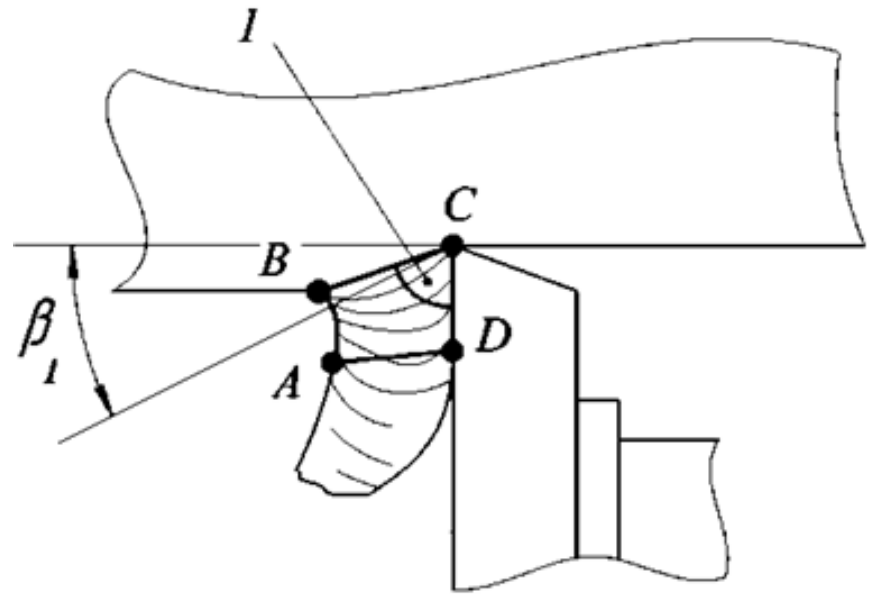

Figure 8: Diagram of chip formation in thermo-frictional turn-milling

plastic and its dimensions and deformations of the material grains in this zone are determined by the intensity of friction on the forward surface.

The process of cutting in thermo-frictional turn-milling is characterized not only by high intensity of deformation, but also by large speeds of deformation. In zone 1 in the most part of chips the texture goes in parallel to each other (see photos Figure 7 b, c, d, k, I), keeping an invariable configuration, however in the chips layer adjacent to the forward surface of the tool the texture lines lose their configuration (see photos Figure $7 \mathrm{a}, \mathrm{g}, \mathrm{i}, \mathrm{n}, \mathrm{o}$ ).

This phenomenon is connected with the slowing-down effect caused by the forward surface of the tool. The more is the friction force operating on the forward surface, the stronger is the chip slowed-down contact layer and the more is bent the texture line adjacent to the forward surface of the tool.

As the process of cutting in thermo-frictional turn-milling is carried out in complicated thermodynamic conditions, the slowing-down effect by the cutting tool becomes so large that it leads to dense accession of a part of chips to the forward surface and formation of the slowed-down layer that is clearly visible in the obtained photos. From this there can be drawn the following conclusion: in the section of plastic contact the chip surface is so densely pressed to the forward surface of the tool that a part of chips moves not on the tool but on the slowed-down layer covering the forward surface.

It is known that the slowed-down layer is usually formed when cutting plastic and viscous materials. In our case the absence of cooling is the main reason for formation of the slowed-down layer in thermo-frictional turn-milling. It should also be noted that in work [7] there was made an assumption that in thermo-frictional turn-milling there appears a current layer owing to which there takes place chips sliding in relation to the current stagnant layer which protects the surface of the frictional mill from wear. This phenomenon defines the features of thermo-frictional turn-milling as a process. For emergence of the current layer there are needed certain conditions from which the major and defining is the appropriate temperature concentrating in the small dimension boundary layer.

On the basis of the available data [20] there can be considered that the value of this temperature fluctuates within the value of the temperature of recrystallization of the machined material. In the paper [7], the value of the chip shrinkage coefficient depending on the feed was calculated. Using methods of calculation according to works $[21,22]$, and also based on results of experimental researches schedules of influence of modes of cutting on value of coefficient of shrinkage of a shaving were received (see Figure 9a, b).

Figure 9 shows the dependence of the chip shrinkage coefficient on the cutting speed and feed. 


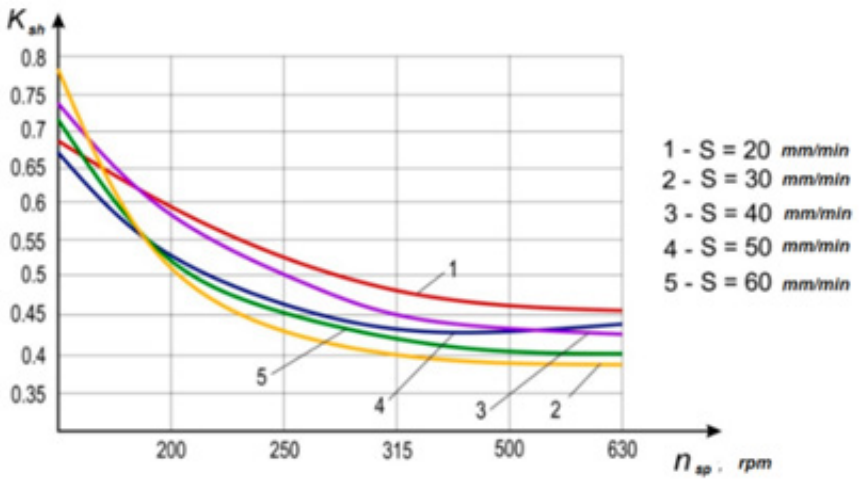

(a)

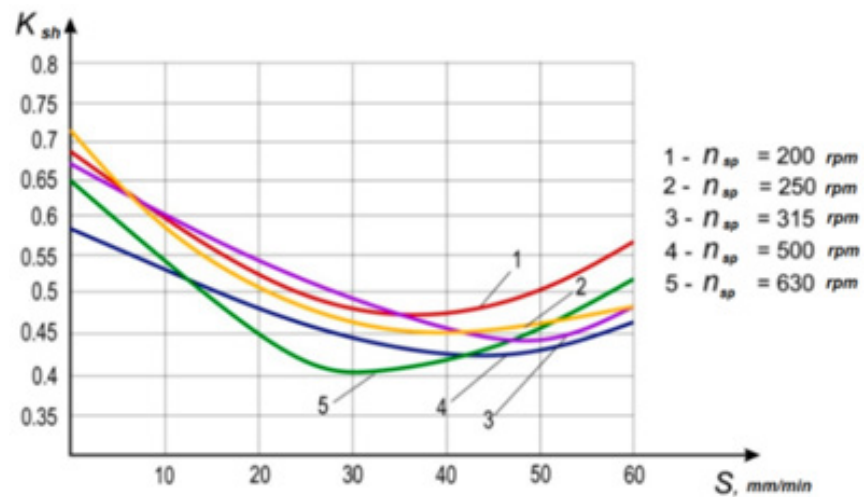

(b)

Figure 9: Graphs of the dependence of the chip shrinkage coefficient on the cutting speed and feed: graph of the effect of the spindle speed on the chip shrinkage coefficient at different feed values (a), graph of the effect of the feed on the chip shrinkage coefficient at different spindle speeds (b)

The graphs show that with increasing feed and spindle speed decreases the value of the chip shrinkage coefficient. The lowest chip shrinkage coefficient is observed at cutting modes: $S=30 \mathrm{~mm} / \mathrm{min} ; n_{s p}=630 \mathrm{rpm}$.

\section{CONCLUSIONS}

It has been established that in the course of thermo-frictional turn-milling there are no structural transformations; the material in contact layers keeps its initial phase state and undergoes changes only owing to plastic deformation.

It has been revealed that separate elements of the flow chip root are deformed in the direction that does not coincide with the position of the shear plane at the angle $\beta_{1}$. It has been established that in thermo-frictional turn-milling there is absent the outgrowth formation as the chips material which is near the place of contact with the tool and is the raw material for the outgrowth is softened, becomes very plastic and will flow in a thin layer on the forward surface of the tool aside, opposite to its movement. It has been revealed that in the course of thermo-frictional turn-milling there takes place dense accession of a part of chips to the forward surface which promotes formation of the slowed-down layer. From here there can be drawn the conclusion that a part of chips moves not on the tool but on the slowed-down layer covering the forward surface preventing its wear.

The authors consider that the main reason for formation of the slowed-down layer when machining 30HGSA steel characteristic of the process of cutting plastic and viscous materials, is the absence of cooling in thermo-frictional turn-milling. However taking into account that the process of cutting in thermo-frictional turn-milling is carried out in complicated thermodynamic conditions, there is needed a more detailed additional study of the process of forming the slowed-down layer.

It is established that with increasing supply $S$ the value of the chip shrinkage coefficient $K_{s h}$ decreases. The higher the chip shrinkage factor, the more work will be required to cut the chips and the more complex the processing process.

\section{REFERENCES}

1. Kravchenko, N.S., Pegashkin, V.F. (2015). Analysis of milling schemes. Materials of the International Scientific and Practical Conference. 2 v. T1. FGAOU VPO «Ural Federal University named after the first President of Russia B.N. Yeltsin», Nizhnetagil Tech. Inst. - Nizhny Tagil: NTI (branch) UFU, P.51-56.

2. Selivanov, A.N., Nasad, T.G., Tormanov, S.Y. (2011). Experimental investigations of chip formation during processing of titanium alloy VT 1-0 with the method of high-speed circumferential milling. Bulletin of the CSTU. №2(56). Issue 2.- P.138-144.

3. Sherov, K.T., Mussaev, M.M., Kokkoz, M.M. (2018). The method of thermofriction milling and milling friction. Patent RK No. 32933 for the invention. Published on July 5th. Bull. Number 25.

4. Khodzhibergenov, D.T., Esirkepov, A., Sherov, K.T. (2015). Rational milling of metals. Russian Engineering Research. Allerton Press, Inc. Vol. 35. No 1. pp. 43-45. DOI: https://doi.org/10.3103/s1068798 $\mathrm{x} 1501013 \mathrm{x}$

5. Sherov, K.T., Sikhimbayev, M.R., Sherov, A.K., Donenbayev, B.S., Rakishev, A.K., Mazdubay, A.V., Musaev, M.M., Abeuova, A.M. (2017). Matematical modeling of thermofrictional milling process using ANSYS WB software. Journal of Theoretical and Applied Mechanics, Sofia, Vol. 47, No. 2, P. 24-33. https://doi.org/10.1515/jtam-2017-0008

6. Sherov, K.T., Sikhimbayev, M.R., Nasad, T.G., Absadykov, B.N., Izotova, A.S., Okimbayeva, A.E., Kuanov I.S. (2020). The research of the steel cutting blade reliability for thermo-frictional processing. News of the National Academy of Sciences of the Republic of Kazakhstan. Series of geology and technical sciences. Volume 1, Number 439, P.122 - 130. https://doi.org/10.32014/2020.2518-170X.15 
7. Sherov K.T., Mussayev, M.M. (2016). Calculation of shrinkage ratio for processing 30KhGSA steel with milling. Mechanics and technology. - Taraz: Publishing house "Taraz University" TarSU them. M.H. Dulati, №3- P.36-42.

8. Juri Olt, Alexander Liyvapuu, Marten Madissoo, Viacheslav Maksarov (2016) Dynamic simulation of chip formation in process of cutting / International Journal of Materials and Product Technology, Vol.53 No.1, pp.1 - 14. DOI: 10.1504/IJMPT.2016.076363

9. Bannov, K.V., Valkevich, K.V., Matveev, V.S. (2006). Analysis of the phenomena of crushing and curling chips. Bulletin of the Kurgan state University. Series "Technical Sciences". - Vol. 2. - Kurgan: Publishing house of Kurgan state University, Part 1. - P. 14-15.

10. Nasad, T.G., Sherov, K.T., Absadykov, B.N., Tusupova, S.O., Sagitov, A.A., Abdugaliyeva, G.B., Okimbayeva, A.E. (2019). Formation management in parts processing regenerated by surfacing. News of the National Academy of Sciences of the Republic of Kazakhstan. Series of geology and technical sciences. Vol. 3, N 435. P. 102-108. DOI: https://doi. org/10.32014/2019.2518-170x.74

11. Komanduri, R., Brown, R.H. (1981). On the Mechanics of Chip Segmentation in Machining. Transactions of the ASME. - J. Eng. Ind. Feb., 103(1) - P.3-51. DOI: https://doi.org/10.1115/1.3184458

12. Sherov K., Mardonov M. Zharkevich O. Mirgorodskiy S. Gabdyssalyk R. Tussupova S. Smakova N. Akhmedov Kh. Imanbaev Y. (2020) Studying the process of tooling cylindrical gears / Journal of Applied Engineering Science (JAES), vol. 18, br. 3, str. 327 332. DOI: 10.5937/jaes18-23794

13. Dudak N., Taskarina A., Kasenov, A., Itybaeva, G., Mussina, Z., Abishev K., Mukanov R. (2017) Hole Machining Based on Using an Incisive Built-Up Reamer // International Journal of Precision Engineering and Manufacturing, Volume 18, Issue 10, Pages 1425-1432. https://doi.org/10.1007/s12541017-0170-9

14. Sherov, K.T., Sikhimbayev, M.R., Absadykov, B.N., Sikhimbayeva, D.R., Buzauova, T.M., Karsakova, N.G., Gabdysalyk, R. (2018). Control's accuracy improvement and reduction of labor content in adapting of ways of metalcutting tools // News of the National Academy of Sciences of the Republic of Kazakhstan. Series of geology and technical sciences. Vol. 6, N 432. P. 170-179. DOI: https://doi. org/10.32014/2018.2518-170x.47
15. Garshin, A.P., Fedotova, S.M., Edited, B.Y. (2018). Material science in 3 volumes. Volume 1. Abrasive materials: textbook for academic bachelor. - 2nd ed., corrected and additional - Moscow: Yurayt Publishing house, $214 \mathrm{p}$.

16. Dudak, N., Itybaeva, G., Kasenov, A., Mussina, Z., Taskarina, A., Abishev K. (2019) Multi-flute drillbroach for precision machining of holes // Scientia Iranica, Vol. 26, Issue 3, P.1415-1426. DOI: 10.24200/sci.2018.5623.1379

17. Yascheritsyn, P.I., Eremenko, M.L., Feldstein, E.E. (1990). Theory of cutting. Physical and thermal processes in technological systems: Studies. for universities. - Int: High school., 512 p.

18. Ryzhkin, A.A. Chuchev, K.G., Klimov, M.M. (2008). Material processing by cutting: study manual - Rostov on D: Phoenix - 411p.

19. Opitz, H., Hucks, H. (1973). The machining process as a problem of Mohr's sliding surface theory for the two- and three-axis stress state, «Werkstattstechnik und Maschinenbau», N 6, pp. 253-260.

20. Kushnazarov, I.K., Sherov, K.T., Altynbaev R.R. (2007). Technology termo-frictional milling with high frequency cooling. High technology in engineering: Collection of scientific articles NTU "KhPI".- Kharkov -Vol.2(15).- P. 134-139.

21. Selivanov A.N. (2011). Increase of productivity and quality of processing of bodies of rotation from titanium alloys by the method of high-speed milling and milling: dis. Cand. tech. sciences. Saratov state tech. University, Saratov.

22. Loladze T.N. (1982). Strength and wear resistance of the cutting tool M.: Engineering - 320p. 